\title{
Optimal Power Loss Minimization using Optimal Size and Location of Shunt Capacitors, and DG
}

\author{
Hesain Milad Alfrd \\ Department of Electrical \&Computer Engineering, College of Engineering, \\ Elmergib University, Libya
}

DOI: https://doi.org/10.21467/proceedings.2.20

* Corresponding author email: hussein.alfared@elmergib.edu.ly

\begin{abstract}
One of the biggest problems that face the electric distribution network is the power losses, which could be reduced for obtaining a good voltage improvement. Two effective case studies have been used to minimize the power losses; a conventional case study which could be represented by installing Shunt Capacitors, and a modern case study which could be represented by installing Distributed generators (DG). This paper presents effective approaches, to obtain the optimal size and location of each of Shunt Capacitors, and DG, based on Newton Raphson Numerical Method. The first approach proposes load flow, and the second approach proposes optimal load flow. A Libyan distribution network was chosen for the discussion and analysis.
\end{abstract}

Keywords: Loss formula, Shunt capacitor, Distributed generation.

\section{Introduction}

Installation of shunt capacitors in the electrical distribution system, has many advantages for many purposes. Inductive loads such as transformers and motors cause lagging power factor which leads to a reduction in capacity, voltage levels, and increasing power losses. Optimal capacitor placement provides a network with the necessary reactive power using Tabu Search method [1]. Various techniques have been applied using capacitor allocation, and every technique has its own advantages, and defects [2]. Shunt capacitors enhance the reactive power control in addition to the system reliability and security in the distribution network. For the compensated and uncompensated networks a state-space method is used to study the reliability index [3]. Minimizing the power and energy losses using a genetic algorithm where the major objective function is to decrease the cost depending on capacitor location and reactive power support [4]. Optimal capacitor location and size to supply with the necessary compensation for the better investment required to satisfy appropriate reactive constraints based on deterministic and genetic algorithm together [5].The improvement of the Distributed Generation technologies has a large impact on power system operation. The renewable energy sources such as solar, wind, hydro, biomass, etc., is the most important motivation for the studies including the integration of DG to the electric grid. Voltage

(C) 2018 Copyright held by the author(s). Published by AIJR Publisher in Proceedings of First Conference for Engineering

Sciences and Technology (CEST-2018), September 25-27, 2018, vol. 1 .
This is an open access article under Creative Commons Attribution-NonCommercial 4.0 International (CC BY-NC 4.0)

AijR license, which permits any non-commercial use, distribution, adaptation, and reproduction in any medium, as long as the original work is properly cited. ISBN: 978-81-936820-5-0 
Optimal Power Loss Minimization using Optimal Size and Location of Shunt Capacitors, and DG

profile improvement and reducing power losses can be obtained by the installation of DG in the distribution network [6]. Essential definitions of DG and their operating constraints as well as their types, classification, and technologies [7]. DG on electric power system contributes to good power quality, voltage profile improvement, and loss reduction [8]. Hybrid PSO \&HBMO algorithm is implemented in optimal placement and sizing of DG in the distribution network in order to decrease the total power losses and obtaining voltage profile enhancement [9]. Genetic Algorithm is also used for optimal size and location of DG with the purpose of supplying necessary real and reactive power to a distribution network whereas the main objective is to minimize system losses and to enhance system reliability and voltage profile [10]. Power Loss Minimization and Voltage Profile Improvement of a Distribution System Using Optimal Size and Location of DG utilized on 11 (KV) real Libyan distribution system [11]. In this paper, the optimum size and location of the shunt capacitor, and DG connected to distribution system is studied by using an optimal control theory with an excellent solution approach (Newton Raphson).

\section{Materials and Methods}

The Newton-Raphson (NR) method has outstanding convergence characteristics for solving non-linear algebraic systems. In comparison with the Gauss-Seidel method, a lesser range of iterations is necessary for convergence provided that, the initial values are not far away from the final solution [12].

\section{Theory and Calculation}

Two case studies were applied to find the optimal size and location of a shunt capacitor, and

DG separately using Newton Raphson method on a power distribution system, the following Computational procedure should be done as follows:

Step 1: Run normal load flow to find the losses before the installation of the capacitor \&DG. Step 2: Run normal load flow after installing unknown shunt capacitor size on each bus.

Step 3: Find the optimal size of the shunt capacitor for each bus using Eq.(4).

Step 4: Compute the total loss using Eq. (1) after placing a shunt capacitor of the optimal size obtained in step 3.

Step 5: Run optimal load flow after installing unknown DG size on each bus.

Step 6: Find the optimal size of DG for each bus using Eq. (3).

Step 7: Compute the total loss using Eq. (1) for each bus by placing DG of optimal size obtained.

Step 8: Locate each of shunt capacitors and DG on the bus at which the loss is minimum. This is the optimum location for a shunt capacitor or DG.

Step 9: Run load flow with each of shunt capacitor and DG to get the final result.

Step 10: The voltage profile has improved after connecting a shunt capacitor and a distributed generator on the optimal location using Eq. (6). 
Hesain Milad Alfrd, CEST-2018, AIJR Proceedings 2, pp.159-165, 2018

\subsection{Mathematical Expressions and Symbols}

Location and size of shunt capacitor \& DG units are decided in such a way that minimum system power loss and desired voltage profile are obtained. Therefore, there is a need to define the system power loss as a function of each of shunt capacitor and DG size and system bus voltages. Hence:

$P_{\text {loss }}=\sum_{i \neq j}^{m} P_{\text {line }}$

Where $\mathrm{P}$ loss: is the real power loss, and $\mathrm{m}$ : is the number of branches in the power system.

$P_{\text {line }(i, j)}=P_{(i)}-P_{(j)}$

$P_{i}=P_{D G i}-P_{D i}=\left|V_{i}\right| \sum_{j=1, j \neq i}^{n}\left|V_{j}\right|\left[G_{i j} \cos \left(\theta_{i}-\theta_{j}\right)+B_{i j} \sin \left(\theta_{i}-\theta_{j}\right)\right]$

$Q_{i}=Q_{D G i}-Q_{D i}=\left|V_{i}\right| \sum_{j=1, j \neq i}^{n}\left|V_{j}\right|\left[G_{i j} \sin \left(\theta_{i}-\theta_{j}\right)+B_{i j} \cos \left(\theta_{i}-\theta_{j}\right)\right]$

where ' $\boldsymbol{i}$ ' is the location of the capacitor or DG unit $(\boldsymbol{i}=1,2,3 \ldots, \mathrm{n})$ and ' $\boldsymbol{n}$ ' is the total number of bus bars in the distribution network. $P_{i}$ and $Q_{i}$ are net real and reactive power injection in the bus ' $\boldsymbol{i}$ ' respectively. $V_{\boldsymbol{i}}$ is the voltage magnitude at the bus ' $\boldsymbol{i}$ ' respectively. PDGi and $Q_{D G i}$ are the real and reactive power generations of DG at the bus ' $\boldsymbol{i}$ '. $P_{D i}$ and $Q_{D i}$ are the real and reactive power demand at the bus ' $i$ '. So objective function is to minimize the power loss considering following constraints:

$\mathrm{P}_{\text {loss }}=\sum_{\mathrm{i}=1}^{\mathrm{n}} \mathrm{P}_{\mathrm{G}(\mathrm{i})}-\sum_{\mathrm{i}=1}^{\mathrm{n}} \mathrm{P}_{\mathrm{D}(\mathrm{i})}$

Where $P_{G(i)}$ is the generated real power in the bus' $\boldsymbol{i}^{\prime}$, and $P_{D(i)}$ is the consumed power in the bus- ${ }^{\prime} \boldsymbol{i}^{\prime}$

Where ' $\boldsymbol{n}$ ' is a number of buses. It should highlight that enhancing the voltage profile depends upon minimizing the voltage

deviations VD as:

$V D=\sum_{i=1}^{n}\left(\left|V_{n}-V_{r e f}\right|\right)^{2}$

Where $\boldsymbol{V}_{\boldsymbol{r e f}}$ is the reference voltage that commonly equals to 1 p.u.

$$
\begin{gathered}
\left|V_{i \min }\right| \leq\left|V_{i}\right| \leq\left|V_{i \max }\right| \\
P_{\text {line }(i, j)} \leq P_{\text {line }(i, j) \max }
\end{gathered}
$$

Proper settings for $\left|V_{i \text { min }}\right|$ and $\left|V_{i \text { max }}\right|$ results in better voltage profile of system.

\section{Results and Discussion}

A normal load flow and optimal load flow program run by Neplan (power simulation software) on a Libyan distribution network to find the optimum size and location for shunt capacitors, and distributed generation (DG). Simulations were carried out on a local distribution system,

Proceedings of First Conference for Engineering Sciences and Technology (CEST-2018), vol. 1 
Optimal Power Loss Minimization using Optimal Size and Location of Shunt Capacitors, and DG

$11 \mathrm{kv}$, called Sileen Al-Bahria, in Khoms / Libya, located on an approximated area $120 \mathrm{~km}^{2}$, and 78 loads.

\subsection{The Consideration of Work}

1) The data of loads obtained in currents, not in active or reactive power, measured per four months (by the general electric company of Libya).

2) The power factor of the loads was unknown. Hence, it considered 0.87 to calculate the active and reactive power.

3) The distribution system is unbalanced, which led to taking the average of the load currents, to represent the system in one line diagram per phase.

4) The load factor is equal to one.

\subsection{Case Study I}

The first case study is a normal load flow approach, which finds the optimal sizes of shunt capacitors installed at each bus, which gives the less loss according to capacitor size.

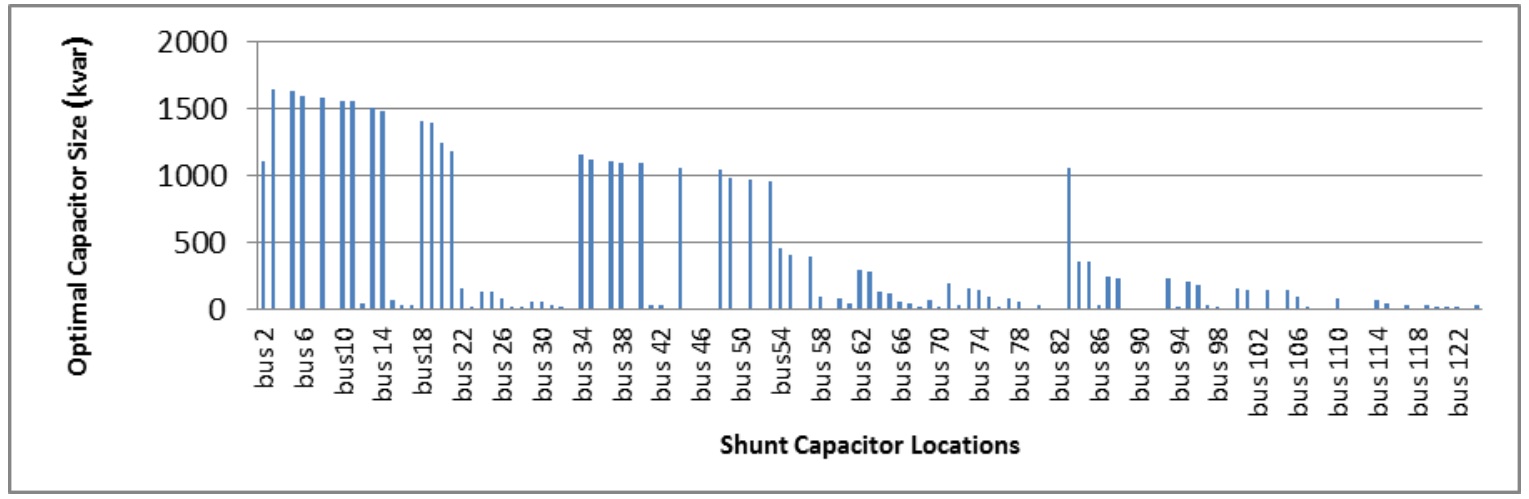

Figure 1: Optimal capacitor size for each bus bar locations

Figure 1 shows the shunt capacitor size, which is the optimal size for each bus bar location.

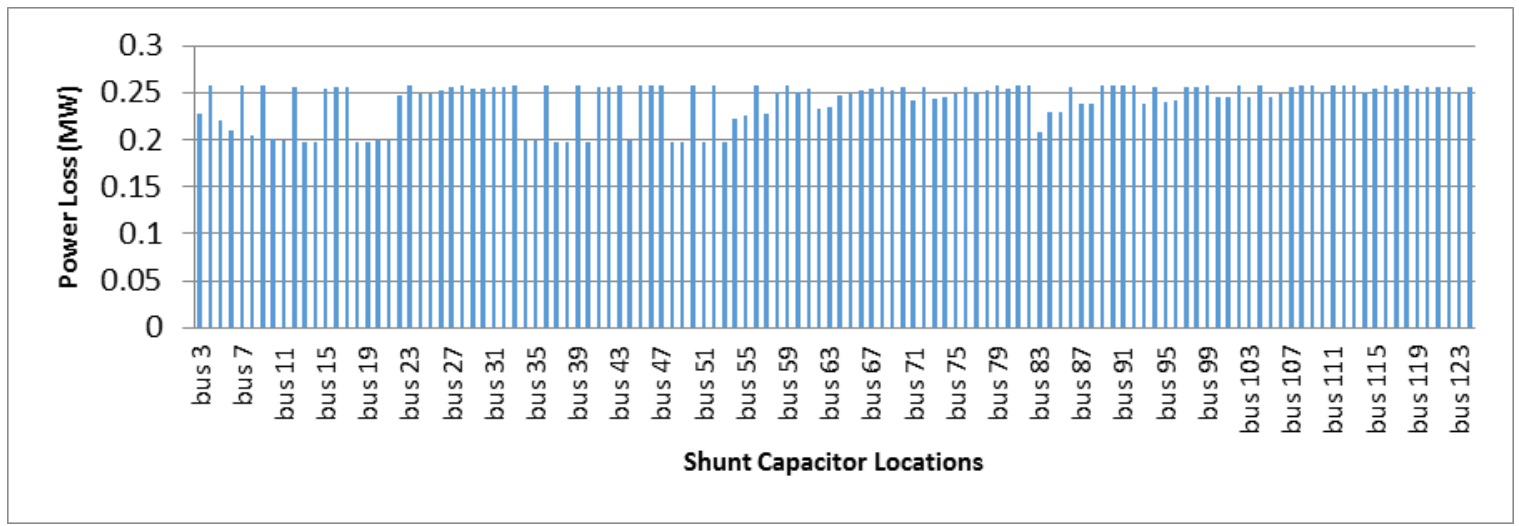

Figure 2: Power losses vs optimal shunt capacitor locations 
Hesain Milad Alfrd, CEST-2018, AIJR Proceedings 2, pp.159-165, 2018

Figure 2 shows the total losses for each optimal shunt capacitor size installed at each busbar in kvar and shows the optimal size which gives the less loss at bus 53 with total losses $0.1967 \mathrm{MW}$, and optimal capacitor size 960.5 kvar.

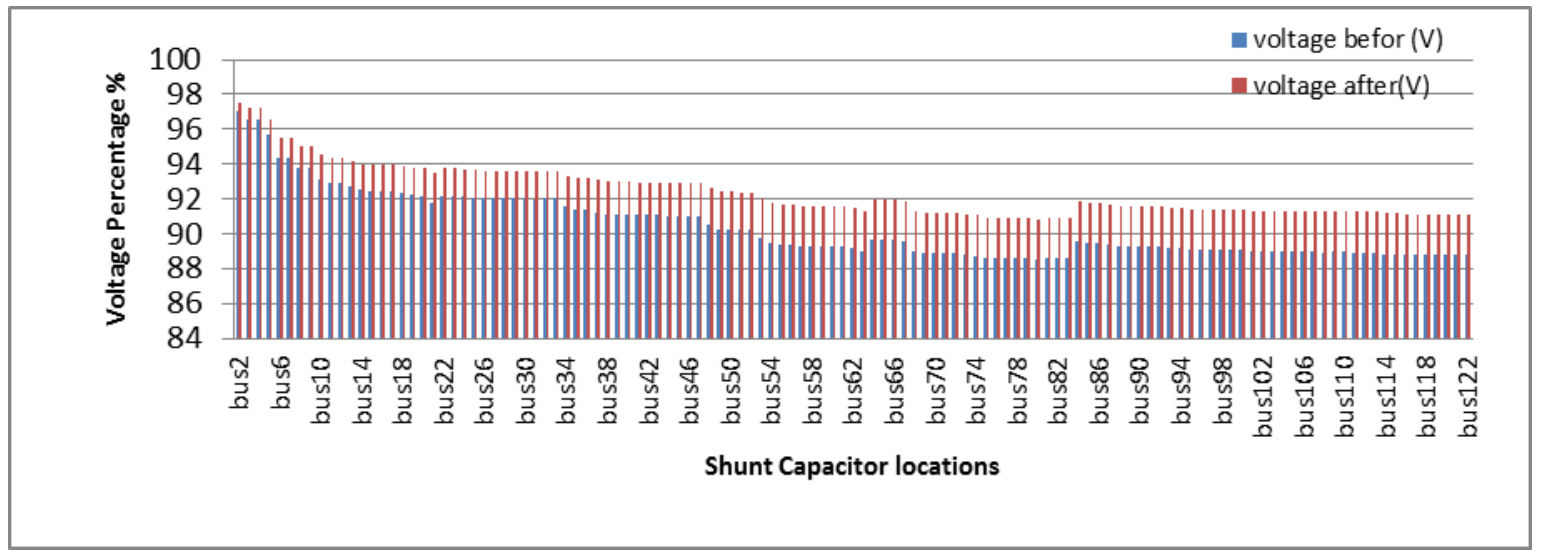

Figure 3: Voltage percentage vs shunt capacitor locations

figure 3 after connecting a shunt capacitor at bus 53 with the optimal size $960.5 \mathrm{kvar}$, shows obtaining a very good voltage improvement for each bus.

\subsection{Case Study II}

The second approach is an application of the optimal load flow by Newton Raphson wherein the optimal size of DG which could be found at each bus, which leads to finding the less loss in the network at all.

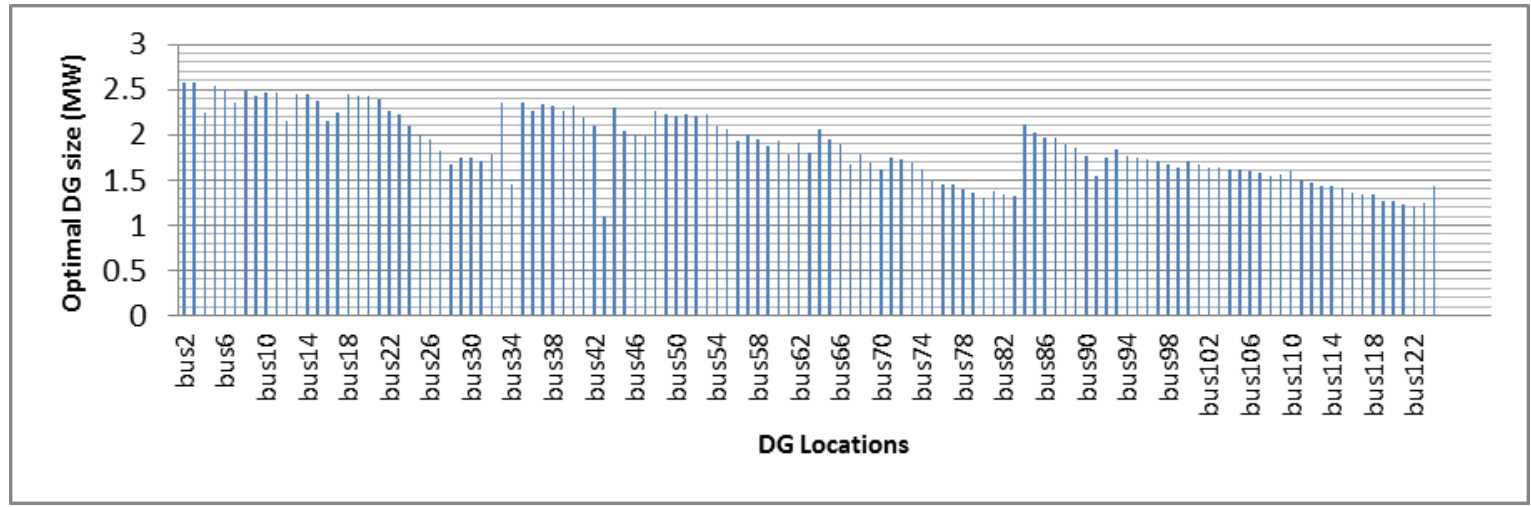

Figure 4: Optimal DG size for each bus bar location

Figure 4 shows the DG size, which is the optimal size for each bus bar location. 


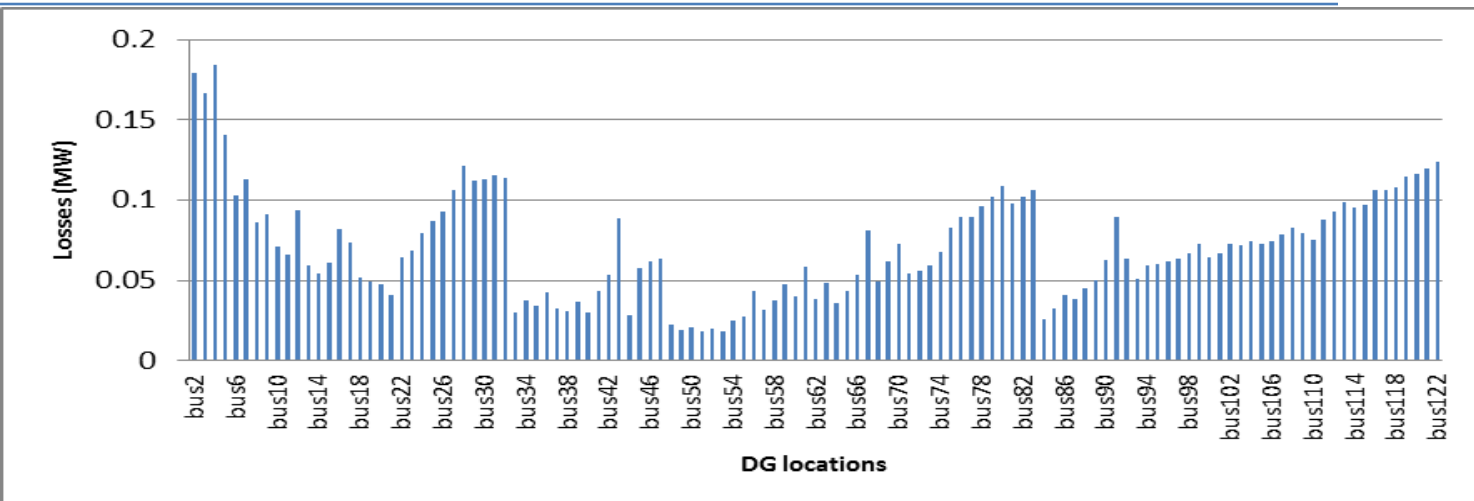

Figure 5: Power losses vs Optimal DG locations

Figure 5, which shows the total losses for each optimal DG size, installed at each busbar in MW, and shows the optimal size which gives the less loss at bus 53 with total losses 0.0292272 MW, and optimal DG size 2.218 MW.

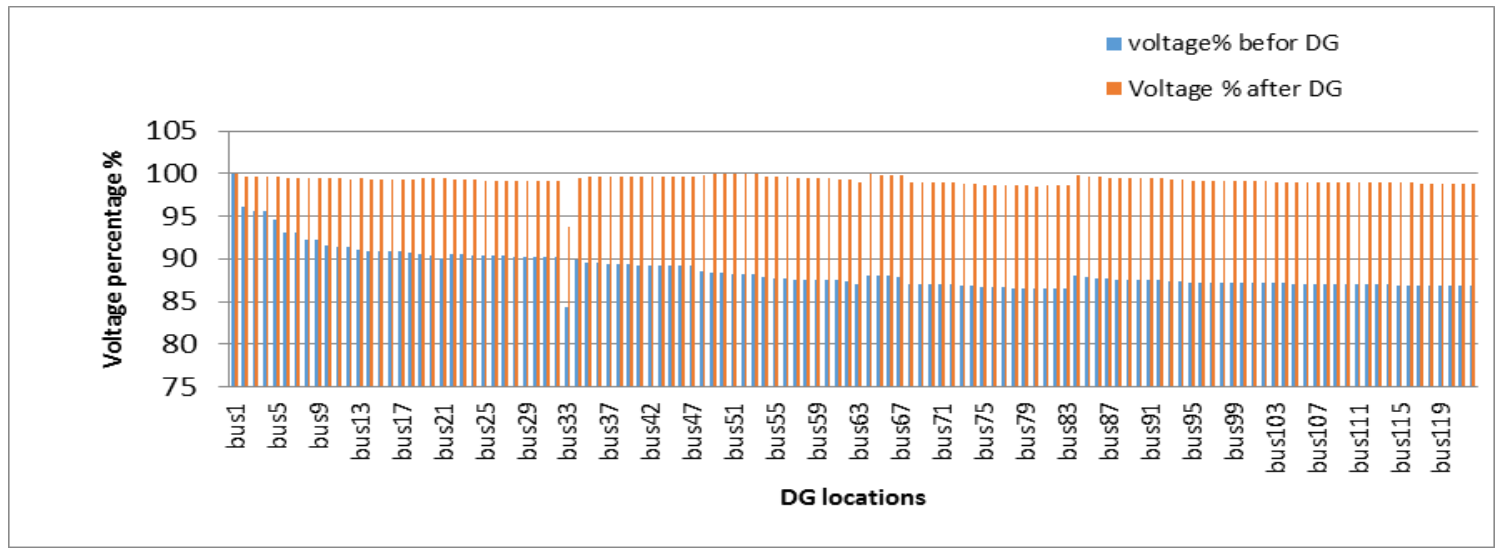

Figure 6: Voltage percentage Vs DG locations

Figure 6 after connecting a distributed generator at bus 53 with the optimal size $2.218 \mathrm{MW}$, shows obtaining a very good voltage improvement for each bus.

Comparison between the two case studies

The following table shows a comparison between the two case studies mentioned above:

Table 1: Optimal placement and sizing of DG and capacitor

\begin{tabular}{|c|c|c|c|c|c|c|c|}
\hline $\begin{array}{c}\text { Case } \\
\text { study }\end{array}$ & $\begin{array}{c}\text { Optimal } \\
\text { bus } \\
\text { location }\end{array}$ & $\begin{array}{c}\text { Optimal } \\
\text { size }\end{array}$ & $\begin{array}{c}\text { Total } \\
\text { Losses } \\
\text { before }\end{array}$ & $\begin{array}{c}\text { Total } \\
\text { losses } \\
\text { after }\end{array}$ & $\begin{array}{c}\text { Power } \\
\text { loss } \\
\text { saving }\end{array}$ & $\begin{array}{c}\text { Voltage } \\
\text { Deviation } \\
(\mathrm{pu}) \\
\text { before }\end{array}$ & $\begin{array}{c}\text { Voltage } \\
\text { Deviation } \\
\text { (pu) after }\end{array}$ \\
\hline Case I & 53 & $960.5 \mathrm{kvar}$ & $0.2583 \mathrm{MW}$ & $0.1967 \mathrm{MW}$ & $0.0616 \mathrm{MW}$ & 1.1716 & 0.7327 \\
\hline Case II & 53 & $2.218 \mathrm{MW}$ & $0.2583 \mathrm{MW}$ & $0.0292 \mathrm{MW}$ & $0.2291 \mathrm{MW}$ & 1.1716 & 0.0120 \\
\hline
\end{tabular}




\section{Conclusions}

In this paper, an efficient optimization algorithm proposed for optimal size and location of shunt capacitor and DG on a Libyan distribution network. This method based on Newton Raphson has an efficient minimization of the real and reactive power losses and voltage difference to retain the voltage limits within the accepted range. Two effective case studies have been used; a conventional case study represented by installing Shunt Capacitors, and a modern case study represented by installing Distributed generators (DG). A real application on a Libyan distribution network by NEPLAN Software is applied and gave good results of loss minimization \& voltage profile. A Comparison between the two case studies showed the difference between them.

\section{References}

[1] R. A. Gallego, A. J. Monticelli, and R. Romero, "Optimal capacitor placement in radial distribution networks", IEEE Trans. on Power Systems, vol. 16, Issue 4, pp. 630- 637, 2001.

[2] H. N. Ng, M. M. A. Salama, and A. Y. Chikhani, "Classification of capacitor allocation techniques", IEEE Trans. on Power Delivery,vol. 15, pp. 387-392, 2000.

[3] Abdel hay A. Sallam, Mohamed Desouky and Hussien Desouky, "Shunt Capacitor Effect on Electrical Distribution System Reliability” IEEE Trans on Reliability, Vol. 43, Issue 1, pp. 170-176, March 1994.

[4] Srinivasan Sundhararajan and Ani1 Pahwa, "Optimal Selection of Capacitors for Radial Distribution Systems using a Genetic Algorithm” IEEE Transactions on Power Systems, Vol. 9, Issue. 3, pp. 1499-1507, August 1994.

[5] Maurizio Delfanti, Gianpietro P. Granelli, Paolo Marannino, and Mario Montagna, Optimal Capacitor Placement Using Deterministic and Genetic Algorithms" IEEE Transactions on power systems, VOL. 15, Issue. 3, pp. 1041- 1046 August 2000.

[6] T. Ackermann, G. Anderson, L. Soder, "Distributed generation: a definition" Electric Power Systems Research, Volume 57, Issue 3, Pages 195-20420, April 2001.

[7] El-Khattam and M.M.A. Salama, "Distributed generation technologies, definitions, and benefits" Electric Power Systems Research, Volume 71, Issue 2, Pages 119-128, October 2004.

[8] P. P. Barker, R. W. de Mello, " Determining the Impact of Distributed Generation on Power Systems: Part 1 Radial Distribution System” IEEE Power Engineering Society Summer Meeting, vol. 3, pp. 1645-1656, 2000.

[9] M. Afzalan, M. A.Taghikhani, "DG Placement and Sizing in Radial Distribution Network Using PSO\&HBMO Algorithms", Electrical Power Distribution Networks (EPDC), 2012 Proceedings of 17th Conference on, vol., no., pp.1-6, 2-3 May 2012.

[10] Carmen L.T. Borges, Djalma M. Falcao, "Optimal distributed generation allocation for reliability, losses, and voltage improvement”, International Journal of Electrical Power \& Energy Systems, Volume 28, Issue 6, Pages 413420, July 2006.

[11] Hussein Alfared, Abdalla I. Fadel, "Power Loss Minimization and Voltage Profile Improvement of a Distribution System Using Optimal Size and Location of Distribution Generation," Libyan conference LICEET 2018, no. 25. March 2018.

[12] J. C. Das, “ Power System Analysis Short-Circuit Load Flow and Harmonics", Marcel Dekker, Inc. 